\title{
Ciliary block (malignant) glaucoma after cataract extraction with lens implant treated with YAG laser capsulotomy and anterior hyaloidotomy
}

\author{
A Halkias, D M Magauran, M Joyce
}

\begin{abstract}
An 84-year-old woman developed high intraocular pressure with a shallow anterior chamber 2 months after an extracapsular cataract extraction with posterior chamber lens implant. The condition did not respond to peripheral iridectomy and removal of the implant but was treated successfully with YAG laser capsulotomy and anterior hyaloidotomy. (Brf Ophthalmol 1992; 76: 569-570)
\end{abstract}

Malignant glaucoma is a rare complication of intraocular surgery. It usually follows glaucoma surgery but has also been reported, among others, after modern cataract surgery. ${ }^{12}$

\section{Case report}

The patient was an 84-year-old woman who had ophthalmic history of bilateral cataracts, bilateral age-related macular degeneration, and an old corneal scar in her left eye. She had a left intracapsular cataract extraction with anterior chamber lens implant in 1985.

Postoperatively she developed what was considered to be pupil block glaucoma with a moderate rise of intraocular pressure (around 30 $\mathrm{mm} \mathrm{Hg}$ ) and a thickening of the anterior hyaloid face which reduced the visual acuity (to $6 / 60$ corrected). Both conditions were successfully treated with YAG laser iridotomy and anterior hyaloidotomy. She was a known hypermetrope with axial lengths of right eye $21 \cdot 17 \mathrm{~mm}$ and left eye $20.60 \mathrm{~mm}$.

She had a right extracapsular cataract extraction with a posterior chamber lens implant in 1990. The surgery was complicated by miosis which, in conjunction with the old corneal scar, made visualisation difficult. A small amount of soft lens matter was left in the 9 o'clock position. The posterior capsule was intact.

Postoperatively the lens matter was absorbed and the visual acuity improved to only 6/24 corrected because of her macular degeneration. Two months postoperatively she developed severe pain in her right eye and was admitted as an emergency.

Her visual acuity was reduced to hand movements. There was perilimbal injection, corneal epithelial oedema, the anterior chamber was shallow especially at 9 o'clock, and the intraocular pressure was $66 \mathrm{~mm} \mathrm{Hg}$. She was treated with intensive pilocarpine drops and systemic acetazolamide; the pressure was then 35 $\mathrm{mm} \mathrm{Hg}$. However the anterior chamber remained shallow. She underwent two surgical iridectomies and the anterior chamber was reformed with Healon. These measures were unsuccessful and the anterior chamber remained shallow. The intraocular pressure was $40 \mathrm{~mm} \mathrm{Hg}$. The implant was removed and the anterior chamber was reformed with Healon. The posterior capsule was intact.

The anterior chamber became shallow again and the intraocular pressure was raised. A diagnosis of malignant glaucoma was made. Atropine, phenylephrine and steroid drops were given with systemic acetazolamide. The anterior chamber deepened for the first time, the intraocular pressure was still high, in the mid thirties $\mathrm{mm} \mathrm{Hg}$.

At this stage it was decided to establish a communication between the fluid which presumably had accumulated in the vitreous and the anterior segment. The YAG laser was used to make a central opening in the posterior capsule and disrupt the anterior hyaloid face. This resulted in an immediate deepening of the anterior chamber and a drop in the intraocular pressure which returned to normal over the next 48 hours. Her medication was gradually discontinued.

The visual acuity is $6 / 24$ corrected, the anterior chamber is deep, and the intraocular pressure remains normal 10 months later.

\section{Discussion}

Malignant glaucoma is characterised by a shallow anterior chamber with persistently high intraocular pressure in spite of the presence of a patent iridectomy. ${ }^{345}$

The pathogenesis involves misdirection of aqueous which becomes trapped within or behind the vitreous. It is still unclear what the initiating event is but it is thought to be related to the particular anatomy of the eye (small eyes) combined with changes such as angle closure, inflammation of the ciliary body which pushes the iris-lens diaphragm forward, blocks the normal pathway of the aqueous, and also possibly causes adhesions of ciliary processes to the vitreous with resultant redirection of the aqueous flow towards the vitreal cavity. There it becomes entrapped, causes bulging of the vitreous, and the initiation of a vicious circle. ${ }^{34}$

In our case we hypothesise that the soft lens matter which remained after the extracapsular procedure caused an inflammatory reaction of the ciliary body with resultant adhesions of the processes to the vitreous and misdirection of aqueous in a predisposed eye. Alternatively, the operative trauma may have resulted in separation of the vitreous base from the pars plana. Misdirected aqueous then could have entered the 
vitreous body. It is known that if one eye suffers an attack of malignant glaucoma the fellow eye is also at risk. In our case we believe that the left eye suffered a 'mild attack' (unrecognised at the time since the intraocular pressure was not impressively high) and that the YAG laser treated the condition, probably not only by the creation of the peripheral iridotomy but also by the rupture of the anterior hyaloid face (which was done for optical reasons - that is, thickening).

The role of the anterior hyaloid as a barrier in this condition is recognised. The medical treatment of malignant glaucoma has been described some years ago. $^{4}$ Surgical treatment includes removal of the lens, posterior sclerotomy, incision of the vitreous, and vitrectomy. The incision of the anterior vitreous can be successfully performed by a YAG laser capsulotomy- hyaloidotomy in aphakic and pseudophakic eyes $^{67}$ and saves the patient another surgical intervention, as our case demonstrates.

1 Duy TP, Wollensak J. Ciliary block (malignant) glaucoma ollowing posterior chamber lens implantation. Ophthalmic Surg 1987; 18: 741-4.

2 Reed JE, Thomas JV, Lytle RA, Simmons RJ. Malignan glaucoma induced by an intra-ocular lens. Ophthalmic Sur 1990; 21: 177-80.

3 Luntz MH, Rosenblatt M. Malignant glaucoma. Surv Ophthalmol 1987; 32: 73-93.

4 Weiss DI, Schaffer RN. Ciliary block (malignant) glaucoma. Trans Am Acad Ophthalmol Otolaryngol 1972; 76: 450-61.

5 Levene RZ. Current concepts of malignant glaucoma. Ophthalmic Surg 1986; 17: 515-20.

6 Epstein DL, Steinert RF, Puliafito CA. Neodymium-YAG laser therapy to the anterior hyaloid in aphakic malignant (ciliovitreal block) glaucoma. Am 7 Ophthalmol 1984; 98: 137-43.

7 Lockie P. Ciliary block glaucoma treated by posterior capsulotomy. Augst NZf Ophthalmol 1987; 15: 207-9. 